\title{
Contrast-Induced Nephropathy: Current practice
}

\author{
Sonali Gupta ${ }^{1 *}$, Pradeep Goyal ${ }^{2}$, Nishant Gupta ${ }^{3}$, Harpreet Sawhney ${ }^{4}$ and Vivek Kumar \\ ${ }^{1}$ Department of Medicine, St. Vincent's Medical Centre, Bridgeport, Connecticut, USA \\ ${ }^{2}$ Department of Radiology, St. Vincent's Medical Centre, Bridgeport, USA
}

${ }^{3}$ Department of Radiology, Columbia University Medical Centre, New York, NY, USA

${ }^{4}$ Department of Radiology, Yale New Haven Health Bridgeport Hospital, Bridgeport, Connecticut, USA

${ }^{5}$ Department of Nephrology, PGIMER, Sector 12 Chandigarh, India

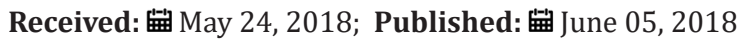

*Corresponding author: Sonali Gupta, Department of Medicine, St. Vincent’s Medical Center, Bridgeport, USA

\begin{abstract}
Contrast induced nephropathy (CIN) is a common cause of hospital acquired acute kidney injury (AKI) and associated with adverse clinical outcomes. There is still debate regarding the exact definition, which has greatly influenced the reported incidence of CIN in literature. Recent studies have challenged the universal concern regarding risk of CIN in general population. It is found to occur more commonly after intra-arterial (IA) administration of contrast as in interventional cardiology and vascular procedures especially in patients with multiple comorbidities and underlying renal impairment. Recent studies report negligible risk after intravenous (IV) contrast administration for modern diagnostic radiological examinations. Since it is a potentially preventable clinical condition, it is imperative for health care professional to be well aware of this entity. All patients undergoing iodinated contrast exposure should be risk stratified and preventive measures should be employed in high risk population. This paper will review the epidemiology, controversies regarding definition, pathophysiology, risk stratification, iodinated contrast commonly used in practice and preventive strategies.
\end{abstract}

Keywords: Contrast Induced Nephropathy; Iodinated Contrast Media; Acute Kidney Injury; Cardiac Angiography; Contrast Enhanced Computed Tomography

Abbreviations: CIN: Contrast Induced Nephropathy; AKI: Acute Kidney Injury; CM: Contrast Media; ICU: Intensive Care Unit; CECT: Contrast Enhanced Computed Tomography; PTCA: Percutaneous Trans-Luminal Coronary Angioplasty; ACR: American College of Radiology; AKIN: Acute Kidney Injury Network; eGFR: Glomerular Filtration Rate; NGAL: Neutrophil Gelatinase-Associated Lipocalin; CES: Cholesterol Embolism Syndrome; ERBP: European Renal Best Practice; KDIGO: Kidney Disease Improving Global Outcomes; NSAIDS: Non-Steroidal Anti-Inflammatory Drugs; HOCM: High Osmolar Contrast Media; LOCM: Low Osmolar Isosmolar CM; HD: hemodialysis; HF: hemofiltration; NAC: N-acetylcysteine; ESUR: European Society of Urogenital Radiology; CAR: Canadian Association of Radiologist; ESRD: End Stage Renal Disease; TOF: Time Of Flight; CKD: Chronic Kidney Disease; NSF: Nephrogenic Systemic Fibrosis; NCCT: Non contrast computed Tomography; $\mathrm{CO}_{2}$ : Carbon Dioxide

\section{Introduction}

Contrast induced nephropathy (CIN) is defined as acute renal impairment after exposure to iodinated contrast media (CM). In the modern era with the advancement of the diagnostic modalities, increase in number of percutaneous coronary and peripheral artery interventions and frequent use of contrast media, CIN has emerged as a common cause of acute renal failure. Mostly, it

results in transient renal impairment; however in patients with multiple comorbidities it can be associated with high morbidity and mortality [1]. It is therefore imperative to identify patients at risk to decrease its occurrence and diagnose it early in course to avoid short and long term clinical adverse effects. It presents a challenging situation that is often encountered by practitioners 
in varied specialties including emergency medicine, nephrology, cardiology, radiology and intensive care unit (ICU). Since CIN represents a form of acute kidney injury (AKI), which is potentially preventable, it is important that clinicians are well aware of this entity and understands the basic pathogenesis involved. The aim of this review article is to discuss pathogenesis of CIN, associated risk factors, different iodinated CM used in clinical practice and their effect on kidney, alternative diagnostic modalities and preventive measures.

\section{Epidemiology}

CIN remains an important cause of in-hospital AKI, accounting for approximately $11 \%$ of the total cases of AKI [1]. Literature on CIN mainly reports it to occur following exposure to iodinated contrast during coronary or peripheral angiography [1,2] or diagnostic imaging, however recent data shows contrast exposure associated with modern radiographic procedure is not associated with significant increase in CIN incidence [3]. Exposure following cardiac or peripheral angiography differs from that during diagnostic imaging in that the injection is intra-arterial, requires catheter and dose of CM is concentrated and abrupt [4,5]. In general population without any risk factor, incidence of CIN is very low; however risk increases as comorbidities increases [1,6,7]. Critically ill patients with baseline renal impairment are particularly susceptible and contrast enhanced computed tomography (CECT) might account for $18 \%$ of AKI cases in this population [8]. Reported incidence of CIN varies with the procedure and is reported to be $11 \%$ after outpatient CECT [9], 4\% following intravenous pyelography [10], $9 \%$ after peripheral arteriography (4), $<3 \%$ following percutaneous trans-luminal coronary angioplasty (PTCA) in patient with normal renal function and as high as $40 \%$ in patient with underlying renal impairment $[2,11,12]$. Studies have documented at least $3.1 \%$ of patients with CIN required renal replacement therapy. In hospital mortality is reported to be $7.1 \%$ in patients with CIN after coronary intervention and as high as $35.7 \%$ in patients requiring dialysis, which further increases to $81.2 \%$ at 2 year [1]. CIN is reported to be independent predictor of poor outcome in patients with diabetes mellitus with or without renal impairment [6].

\section{Definition}

Post- contrast acute kidney injury (PC-AKI) is often defined as acute renal impairment occurring within 48hours of exposure to intravascular iodinated CM. It is a correlational diagnosis and can occur irrespective of $\mathrm{CM}$ being cause of renal deterioration. In contrast, CIN comes under subgroup of PC-AKI and is a causative diagnosis. In literature, CIN has been defined as relative change in the baseline serum creatinine (> 25-50\%) and absolute elevation from baseline serum creatinine (>0.5-2 mg/dL) [1315]. Temporal relationship between exposure to $\mathrm{CM}$ and rise in serum creatinine along with exclusion of other causes of AKI are crucial for the diagnosis of CIN. Defining set criteria for diagnosis is important as incidence of CIN in clinical practice can vary greatly with small change in serum creatinine. An absolute increase of serum creatinine by $\geq 0.5 \mathrm{mg} / \mathrm{dL}$ from baseline is still commonly used definition of AKI [16]. Another well-known criterion for CIN proposed by Barrett and Parfrey in early 1990s was an absolute increase in serum creatinine levels by $\geq 0.5 \mathrm{mg} / \mathrm{dL}$ or a relative increase of $\geq 25 \%$ in serum creatinine from baseline within 72 hours after contrast exposure [17]. However, for purpose of standardizing the definitions, recently American College of Radiology (ACR) has recommended using the AKIN (Acute Kidney Injury Network) criteria to define CIN. It employs absolute serum creatinine increase $>0.3 \mathrm{mg} / \mathrm{dl}$ or $\geq 50 \%$ ( $\geq 1.5$ times) percentage increase in serum creatinine or $\leq 0.5 \mathrm{~mL} / \mathrm{kg} /$ hour urine output for at least 6 hours within 48hours of exposure to define AKI [18]. In clinical practice, serum creatinine concentration is commonly used measure of renal function; however it has its own limitations. There is often delay between renal insult and rise of serum creatinine, which delays the diagnosis. It is also affected by other factors including age, gender, nutritional status, volume status, hyper catabolic state, muscle mass and concomitant use of other medications, therefore it is important to interpret results in appropriate clinical settings $[19,20]$. Changes in serum creatinine concentration are not linearly related to changes in effective glomerular filtration rate (eGFR,) because of which small changes in eGFR can often go unnoticed. Normal serum creatinine is actually maintained till GFR or creatinine clearance is reduced by nearly $50 \%$ [20].

\section{Diagnosis}

Diagnosing CIN is challenging. It is important to follow systemic approach while evaluating patient with AKI. CIN is a diagnosis of exclusion after other causes of AKI (prerenal/intrinsic/post renal) have been ruled out. There is temporal relationship with contrast exposure, however this should not preclude from searching for other reversible causes of AKI, which may coexist [13-15]. Periprocedural hypotension, bleeding, release of athero-embolic material and use of catheter exchanges may further complicate renal tubular injury after angiography [21]. After exposure to intravascular iodinated contrast, serum creatinine typically rises within the first 24-48 hours, peaks at 3-5 days and returns close to baseline within 1-3 weeks. In most cases, it is asymptomatic and has no significant clinical consequences. However, in rare cases it can lead to oliguria or anuria, irreversible renal damage and need for renal replacement therapy. Basic work up includes clinical assessment, urine output, urinalysis and renal imaging. Volume depleted state can predispose patient to CIN; however CIN can result in intrinsic renal injury with tubular necrosis in extreme cases. Finding on urinalysis may include muddy brown granular cast, tubular epithelial cells and minimal or no proteinuria. Urine examination is neither sensitive nor specific to diagnose CIN, however its usefulness is mainly to exclude underlying glomerular disease or acute interstitial nephritis [22]. Urine studies may show intrinsic renal injury picture with urine sodium $<10 \mathrm{mEq} / \mathrm{L}$, fractional excretion of sodium $<1 \%$ and urine osmolality $<350$ 
mOsm/kg. Persistent nephrogram (Figure 1) may be incidentally seen on follow up imaging because of delayed clearance of contrast [23].

Timing of serum creatinine rise after contrast exposure in literature has been reported to be 24-72hours. However, it is speculated that renal damage actually begins soon after exposure to intravascular iodinated contrast. In study by Ribichini et al. [24], it is reported that measuring change in serum creatinine from baseline within 12 hours of contrast exposure significantly predicted occurrence of CIN and was associated with renal damage after 30days [24]. However, relying on serum creatinine for diagnosis of renal injury has its own limitation as discussed above, therefore finding of specific biomarkers that could predict early diagnosis of CIN is desirable. Recently, it has been proposed to classify these biomarkers into two group, namely, (1) reflecting change in renal function (e.g. cystatin C) and (2) representing renal damage (e.g. Plasma or urine neutrophil gelatinase-associated lipocalin (NGAL), interleukin-18\} [25]. Briguori et al. [26] reported increase in levels of cystatin $\mathrm{C} \geq 10 \%$ at $24 \mathrm{~h}$ after PTCA had $100 \%$ sensitivity and $85.9 \%$ specificity for the prediction of CIN [26].

Another condition often encountered after exposure to CM especially catheter related studies is cholesterol embolism syndrome (CES). It can be challenging to distinguish the two conditions clinically; however it is important as both have different treatment approach. CES is usually a rare entity and renal impairment typically develops gradually over 3-8weeks after the procedure. It is a multisystem disease caused by dislodgement of cholesterol crystals from atherosclerotic plaque and occlusion of peripheral arterioles. Other peripheral sign that can help clinch the diagnosis include live do reticularis, petechiae, digital gangrene, splinter hemorrhage and Hollenhorst plaques on ophthalmological examination. Laboratory studies may show peripheral eosinophilia, hypocomplementemia and high erythrocyte sedimentation rate. Spectrum of presentation is varied ranging from mild and asymptomatic to life threatening complications. CES is associated with significantly worse long term renal effects as compared to CIN and is suspected when multiple oral dysfunction occurs following coronary angiography [27].

\section{Pathophysiology}

Kidneys are particularly susceptible to ischemic injury in setting of delicate micro vascular circulation, which is particularly vulnerable to systemic and local hypo perfusion. Pathogenesis of CIN is multi factorial and still not completely understood. Interplay of factors including medullary hypoxia, oxidative stress, im balance of renal vaso constrictive and vaso dilatory mediators, changes in renal perfusion and direct tubular toxicity of $\mathrm{CM}$ has been suggested [28-30]. Two main mechanisms responsible are direct tubular toxicity of $\mathrm{CM}$ and changes in renal micro vascular hemo dynamics. Recently, high end diastolic pulmonary arterial blood pressure and left anterior descending artery lesion has been independently associated with development of CIN, pointing towards role of hemo dynamics and cardiac dynamics in its pathogenesis [31].

\section{Effect of CM on Renal Tubules}

$\mathrm{CM}$ is freely filtered from renal glomerulus and increases the tubular osmolality. It has direct cytopathological effects on tubular cells, which affects energy metabolism and impairs intracellular transport. Histopathologically, these changes consist of tubular cell vacuolization, necrosis and termed as osmotic nephrosis. There has been conflicting evidence to support precipitation of intratubular proteins triggered by CM. Actually it is proposed that CM induced cellular injury might be the inciting event responsible for CIN which triggers the cascade rather than hypoxia or hypoperfusion. Osmolality, viscosity and ionic properties of CM contribute to its nephrotoxicity. High osmolar CM have been shown to affect erythrocyte deformability, leading of stacking of blood cells and affecting blood flow in animal models. Another mechanism reported is mitochondrial dysfunction and release of catalytic iron, which serve as catalyst in oxidative reactions leading to production of free radicles [28-30].

\section{Effects on Renal Microvascular Hemodynamics}

Animal model have suggested that intra-arterial contrast infusion results in biphasic renal perfusion, with initial transient vasodilation followed by sustained prolonged vasoconstriction. Renal medullary perfusion and oxygen tension is lower than outer renal cortex under normal physiological state and thick ascending loop of henle in outer renal medulla has high oxygen requirement exacerbating relative medullary hypoxia. CM further aggravates this hypoxia by causing osmotic diuresis leading to increased sodium transport to thick ascending limb and subsequently increased oxygen extraction. Total medullary hypoxia is actually combination of increased oxygen demand of tubular cells and changes in regional renal microcirculation [32,33]. Subclinical CIN can occur in majority of patients following contrast exposure; however it goes undetected as healthy individuals have intact tubular repair mechanism that prevents clinically significant renal damage. In contrast, in patients with comorbidities like baseline renal impairment and diabetes mellitus even average dose of contrast can have clinical implications in setting of poor reparative mechanism and baseline reduced functional nephrons [34].

\section{Risk Factors}

Various risk factors have been described which increases the risk for development of CIN after exposure to iodinated CM. These can be broadly divided into intrinsic or patient related and external or procedural/contrast related. Among the patient related factors, baseline renal impairment (GFR $<60 \mathrm{~mL} / \mathrm{min}$ per $1.73 \mathrm{~m} 2$ ) and diabetes mellitus are the two important independent risk factors that are commonly coexisting in vascular patient population $[7,35]$. However, recent analyses by McDonald [16] and Davenport et al. [36] have found increased incidence of CIN in diabetes only 
if renal function is compromised (GFR $<30 \mathrm{~mL} / \mathrm{min} / 1.73 \mathrm{~m} 2$ ) $[16,36]$. Studies have reported significant risk for CIN if baseline serum creatinine concentration is $\geq 1.3 \mathrm{mg} / \mathrm{dL}$ in men and $\geq 1.0$ $\mathrm{mg} / \mathrm{dL}$ in women, mostly equivalent to an eGFR $<60 \mathrm{~mL} / \mathrm{min} / 1.73$ $\mathrm{m} 2$ [37]. In light of recent studies, European Renal Best Practice (ERBP) along with Kidney Disease Improving Global Outcomes (KDIGO) guidelines suggest that the threshold at which actual risk for CIN increases could be lowered to $45 \mathrm{~mL} / \mathrm{min} / 1.73 \mathrm{~m} 2$ [38]. Other established risk factors include advanced age ( $\geq 70$ years), dehydration, anemia, vascular disease, hypertension, coronary artery disease, congestive heart failure, smoking and concomitant use of other medications including metformin, non-steroidal anti-inflammatory drugs (NSAIDS), diuretics or calcium channel blockers.

It was long thought that patients with multiple myeloma have increased risk CIN secondary to precipitation of myeloma proteins in the renal tubules. However, recent studies propose that contrast studies can be safely performed in myeloma patients with normal renal function provided there is no dehydration. Also, studies have reported acute urate nephropathy in patients with hyperuricemia, particularly leukemic patients on chemotherapy, secondary to uricosuric property of $\mathrm{CM}$, however recent studies have failed to show independent association between the two $[21,39]$. Extrinsic or contrast related factors includes type of CM, route of administration, dose of $\mathrm{CM}$ and numbers of contrast exposure. Procedure related factors may include urgent or emergent procedure, use of intra-aortic balloon pump, delayed reperfusion and nature of procedure [12,21,39]. Various risk scoring have been proposed to stratify the risk for CIN. One of them reported by Mehran et al. [6] included eight variables namely age $>75$ years, anemia, hypotension, diabetes mellitus, chronic congestive heart failure (CHF), acute pulmonary edema, chronic kidney disease, use of intra-aortic balloon pump and increase volumes of $\mathrm{CM}$. Total risk score $\geq 16$ was associated with $57 \%$ risk of CIN with $13 \%$ of patient requiring dialysis [40]. Another simple risk scoring, which has shown to have clinically significant predictive value for CIN, is ACEF score. It uses three variables, namely age, creatinine level and ejection fraction and has been developed for patients undergoing coronary angiography $[41,42]$.

\section{Iodinated CM}

Type of Iodinated CM: Commonly available CMs are benzoic acid derivatives with three iodine atoms. High osmolar CM (HOCM), with osmolality up to eight times that of plasma were frequently used in past and had higher incidence of CIN. To decrease the osmolality, several approaches were considered including production of non-ionic agents, which resist dissociation in solution or by producing double benzoic acid rings. Low osmolar (LOCM) and isosmolar CM (IOCM) are commonly used nowadays and associated with low nephrotoxicity [43]. (Table1) descries the properties of $\mathrm{CM}$. The adverse effect of $\mathrm{CM}$ is mainly related to its osmolality, ionicity, viscosity and iodine content. Viscosity instead of osmolality is responsible for vascular resistance [44]. Though IOCM has lower osmolality, because of its dimeric structure it has more viscosity than LOCM. There are conflicting results in studies comparing LOCM with IOCM and in most, no difference was found with respect to renal safety [45]. KDIGO guideline recommends use of LOCM or IOCM instead of HOCM however due to lack of data, there is no recommendation regarding preference of IOCM over LOCM [46]. However, CIN Consensus Working Panel recommends use of nonionic IOCM in patients with high risk for CIN undergoing coronary angiography, whereas IOCM or LOCM can be used for intravenous administration of contrast [47]. The current Canadian Association of Radiologists (CAR) consensus recommends use of $\mathrm{CM}$ depending upon route of administration of contrast and renal function; LOCM or IOCM should be used if eGFR $<45 \mathrm{~mL} / \mathrm{min}$ for intravenous exposure and GFR $<60 \mathrm{~mL} / \mathrm{min}$ for intra-arterial CM studies [48]. Many radiology department now-a-days uses IOCM in high risk patient population, especially with severe renal impairment with eGFR $<30 \mathrm{~mL} / \mathrm{min}$. Local hospital protocols based on guidelines can be used to decide between IOCM and LOCM.

Table 1: Properties of contrast media (information taken from manufacturer manual).

\begin{tabular}{|c|c|c|c|c|}
\hline Type of CM & $\begin{array}{l}\text { Generic } \\
\text { Name }\end{array}$ & Ionicity & Dimerization & $\begin{array}{c}\text { Iodine } \\
\text { Content } \\
\text { (mg/ml) }\end{array}$ \\
\hline \multirow{3}{*}{$\begin{array}{c}\text { High } \\
\text { osmolar CM } \\
\text { (HOCM) }\end{array}$} & Diatrizoate & Ionic & Monomer & $140-462$ \\
\hline & Iothalamate & Ionic & Monomer & $141-480$ \\
\hline & Ioxithalamate & Ionic & Monomer & $120-380$ \\
\hline \multirow{7}{*}{$\begin{array}{c}\text { Low } \\
\text { osmolar CM } \\
\text { (LOCM) }\end{array}$} & Ioxaglate & Ionic & Dimer & $160-350$ \\
\hline & Iohexol & Nonionic & Monomer & $180-350$ \\
\hline & Iopamidol & Nonionic & Monomer & $150-370$ \\
\hline & Ioversol & Nonionic & Monomer & $160-350$ \\
\hline & Iopromide & Nonionic & Monomer & $150-400$ \\
\hline & Iobitridol & Nonionic & Monomer & $250-350$ \\
\hline & Iomeprol & Nonionic & Monomer & $150-400$ \\
\hline $\begin{array}{l}\text { Iso osmolar } \\
\text { CM (IOCM) }\end{array}$ & Iodixanol & Nonionic & Dimer & $150-320$ \\
\hline
\end{tabular}

Dose of CM: A number of studies have shown contrast volume to be independent risk factor for subsequent development of CIN after coronary or peripheral angiography [39]. Both volumes of contrast and iodine content needs to be carefully considered taking in account renal safety and optimum imaging. Iodine content is important determinant of image enhancement and degree of attenuation achieved. Iodine content for most of the commonly used contrast ranges from 300 to $370 \mathrm{mg} / \mathrm{ml}$. Low dose of CM defined as $<30-125 \mathrm{ml}$ or $<5 \mathrm{mg} / \mathrm{kg}$, is less nephrotoxic and 
associated with lower risk of CIN. However, AKI can even occur with small (30 mL) volumes of iodinated CM, ruling out threshold effect. Some reports suggest performing staged angiography particularly when large volume of contrast use is anticipated, however this is solely dependent on clinical situation [39,43]. Brown et al.[49] proposed formula and use of "maximal allowable contrast (MAC) dose" (contrast volume limit $[\mathrm{ml}=5 \times$ body weight $\{\mathrm{kg}\}] /[88.4 \times$ SCr $\{\mu \mathrm{mol} / \mathrm{l}\}])$, which correlated, with development of CIN [49]. Whenever possible lowest dose of contrast should be used by incorporating MAC as a part of pre-procedure contrast 'Time-Out'; especially in patients with high risk factors when other alternative modalities cannot be used.

Route of Administration: This is procedure dependent. Intraarterial (IA) injection of iodinated contrast is associated with higher risk of CIN compared to intravenous (IV) administration. Proposed mechanism behind greater risk after IA exposure is amount of contrast directly reaching kidneys if contrast is administered directly in abdominal aorta or renal arteries. Risk is less if contrast is given below origin of renal arteries and minimal risk after IV administration $[4,43]$. Recent studies by McDonald et al. [16] and Daveport et al. [36] using "propensity matching" as statistical tool in order to compare incidence of CIN in patients who received IV contrast for CECT to control group, found that occurrence of CIN in this population is rare and if it occurs it happens in patients with baseline severe renal impairment $\left(\mathrm{eGFR}<30 \mathrm{ml} / \mathrm{min} / 1.73 \mathrm{~m}^{2}\right)$ $[16,36]$.

Repeat Contrast Exposure: Multiple dose exposure of contrast within short period of time is well-documented risk factor for CIN [40,43,50]. It is believed that at least 24 hours interval should be considered between two contrast exposures as it takes approximately 20 hours to eliminate contrast from the body, provided patient has normal renal function. Guitterez et al. [51] demonstrated renal impairment may persist for 10 days after contrast exposure and duration of renal impairment is dependent on baseline renal function. Therefore, repeat exposure should be delayed in patients with chronic kidney disease to allow time for renal recovery [51].

Alternative Imaging Modalities to Prevent CIN: In patients with high risk for CIN, alternative imaging modalities should be chosen after proper risk benefit discussion with the patient. Though contrast enhanced imaging have its own advantages particularly for the diagnosis of inflammatory/ infectious disease and neoplastic conditions as well as diagnosis and treatment of vascular diseases, it is important for the clinicians to be well aware of alternative modalities like ultrasonography, carbon dioxide (CO2) angiography and magnetic resonance imaging (MRI) with or without gadolinium (Table 2). In patients at risk for CIN every effort should be made to avoid iodinated contrast if possible. Non contrast computed tomography (NCCT) is preferred for diagnosis of intracranial hemorrhage, fracture or dislocation and interstitial lung disease [52].

Non contrast MRI [53] including Steady-state free precession MRI (SSFP), Phase contrast MRI, time of flight (TOF) MR angiography should be employed in appropriate setting as described in (Table 2). Gadolinium based contrast agents can be used in patients at risk of CIN, however it is best avoided in patients on dialysis and with severe renal impairment especially chronic kidney disease (CKD) Stage 4 and 5 for concerns of nephrogenic systemic fibrosis (NSF) $[54,55] . \mathrm{CO}_{2}$ angiography is another useful modality often used in various diagnostic and therapeutic interventions when exposure to CM must be avoided to prevent CIN or patient is allergic to iodinated contrast [56]. It is highly soluble, non-allergic, inexpensive and readily available gas with low viscosity relative to blood. For some procedures, $\mathrm{CO}_{2}$ angiography is actually superior to conventional CT including better visualization of collateral circulation, enhanced vascular filing in central venography, detection of $\mathrm{AV}$ shunting in tumors and detection of occult GI bleeding. It can be used in patients with chronic lung disease with caution if sufficient time is allowed for elimination of gas from the body. However, it has some limitations as well. It is preferably used for infradiaphragmatic arteriography due to concerns of neurotoxicity. Other complication limiting its use is vapor lock or air trapping which increases with simultaneous use of nitrous oxide. Another limitation for its use is cumbersome delivery system and risk of error of measurement of vessel size, which is dependent on injection technique [56].

\section{Special Consideration With Use of Iodinated CM:}

a) Met Formin Use: Metformin has not been recognized as independent risk factor for developing CIN, however serious complications like lactic acidosis can rarely develop in patients on metformin, if they subsequently develop AKI after contrast exposure. Whether it should be stopped in all patients anticipating contrast exposure or only in patients with underlying renal impairment and how earlier it should be stopped is still matter of controversy. The monogram for Glucophage (metformin) recommends that it should be discontinued at the time of or before the procedure in all patients, withheld for at least 48 hours subsequent to the procedure, and restarted only after confirmation of normal renal function [57]. The European Society of Urogenital Radiology (ESUR) (Table 3) and Canadian Association of Radiologist (CAR) consensus recommends holding metformin at the time contrast exposure in patient with normal renal function and 48 hours before in patients with preexisting chronic kidney disease $[48,58]$. However, ACR recommends withholding it for $48 \mathrm{hrs}$ before exposure only in patients with marked renal impairment (eGFR $\leq 30 \mathrm{~mL} / \mathrm{min} / 1.73 \mathrm{~m}^{2}$ ) or undergoing intra-arterial catheter studies and no need to discontinue or withhold if eGFR $>30$ $\mathrm{mL} / \min 1.73 \mathrm{~m}^{2}$ ) [59]. 
Table 2: Alternative non-iodinated contrast and non-contrast diagnostic imaging modalities.

\begin{tabular}{|c|c|c|c|}
\hline $\begin{array}{l}\text { Alternative } \\
\text { Modalities }\end{array}$ & Indication & Limitations & Notes \\
\hline $\begin{array}{l}\text { Ultrasonography } \\
\text { with color } \\
\text { Doppler }\end{array}$ & $\begin{array}{l}\text { Detection of gallstones, acute cholecystitis and biliary obstruction. } \\
\text { Appendicitis in childrens. Hydronephorosis or ureteral stone. Acute } \\
\text { or chronic pelvic pain in female such as ovarian cysts, hemorrhagic } \\
\text { cysts, ovarian torsion, ectopic pregnancy, and pelvic inflammatory } \\
\text { disease. Solid vs cystic adenexal mass with evaluation of internal } \\
\text { vascularity, Acute scrotal emergency in male such as testicular } \\
\text { torsion or epididymo-orchitis. In unstable trauma patients, a } \\
\text { FAST* scan can be used to assess for free fluid. Assessment of } \\
\text { the extracranial carotid arteries for atherosclerotic disease. For } \\
\text { evaluation of lower extremity DVT. Assessment of thyroid nodules. }\end{array}$ & $\begin{array}{l}\text { Operator } \\
\text { dependent }\end{array}$ & $\begin{array}{l}\text { Non-ionizing, so useful in children } \\
\text { and in women of child-bearing age, } \\
\text { pregnancy. No intravascular contrast } \\
\text { is required. Better than CT for gall } \\
\text { stones detection, ovaian and testicular } \\
\text { torsion, Soid vs cystic adenexal mass } \\
\text { differentiation and assessment of } \\
\text { thyroid nodules. }\end{array}$ \\
\hline $\begin{array}{l}\text { Carbon dioxide } \\
\text { angiography }\end{array}$ & $\begin{array}{l}\text { Infra-diaphragmatic intra-abdominal arteriography and interven- } \\
\text { tions (renal, mesenteric, transplant organs, aortoiliac), } \\
\text { Peripheral and central venography, IVC filters placement and retriev- } \\
\text { al, portovenogrpahy, planning hemodialysis access and interventions, } \\
\text { vascular malformation detection and intervention. }\end{array}$ & $\begin{array}{l}\text { Avoided for } \\
\text { coronary } \\
\text { or cerebral } \\
\text { angiogram, in } \\
\text { patients with } \\
\text { COPD, forms vapor } \\
\text { lock if use along } \\
\text { with nitrous oxide }\end{array}$ & $\begin{array}{l}\text { Superior to ICM for detection of occult } \\
\text { bleeding site, collateral circulation, } \\
\text { arterio-venous shunting in tumors, for } \\
\text { detection of reconstituted vessel distal } \\
\text { to occlusion, visualization of portal } \\
\text { splanchnic veins. Non-allergenic, } \\
\text { non-nephrotoxic, inexpensive. }\end{array}$ \\
\hline $\begin{array}{l}\text { 2D and 3D-TOF } \\
\text { MR angiography }\end{array}$ & $\begin{array}{l}\text { 3D-Cerebral arteriography for stenosis, aneurysm and AVM or AVF. } \\
\text { 2D and 3D-Cervical arteriography for stenosis, dissection and AVM or } \\
\text { AVF. Cerebral venography for dural venous sinus thrombosis. }\end{array}$ & $\begin{array}{l}\text { Poorer resolution } \\
\text { compared with } \\
\text { conventional an- } \\
\text { giography, motion } \\
\quad \text { artifact }\end{array}$ & No contrast is required. \\
\hline $\begin{array}{l}\text { 3D ECG- } \\
\text { synchronized } \\
\text { or peripheral } \\
\text { pulse gated } \\
\text { half-Fourier fast } \\
\text { spin echo MR } \\
\text { angiography }\end{array}$ & $\begin{array}{l}\text { Evaluation of vessel morphology of peripheral MRA and MRV,Abdom- } \\
\text { inal vessels including porto-venography }\end{array}$ & $\begin{array}{l}\text { Susceptibility to } \\
\text { field heterogeneity, } \\
\text { Requirement of } \\
\text { personnel having } \\
\text { expertise in imag- } \\
\text { ing, post-process- } \\
\text { ing and interpre- } \\
\text { tation. }\end{array}$ & $\begin{array}{l}\text { No contrast is required, short } \\
\text { acquisition time than Phase contrast } \\
\text { and TOF MRA }\end{array}$ \\
\hline $\begin{array}{l}\text { Phase contrast } \\
\text { MR imaging }\end{array}$ & $\begin{array}{c}\text { Quantitative flow measurement in arteries of head, neck, thoracic } \\
\text { and abdominal aorta. Assessment of pulmonary flows and pressure } \\
\text { in pulmonary hypertension, congenital heart disease, renal artery } \\
\text { stenosis. }\end{array}$ & $\begin{array}{l}\text { Poorer resolution } \\
\text { compared with } \\
\text { conventional an- } \\
\text { giography, motion } \\
\text { artifact, long acqui- } \\
\quad \text { sition time }\end{array}$ & $\begin{array}{l}\text { No exposure to ionizing radiation, } \\
\text { evaluation of blood flow and blood } \\
\text { vessel morphology }\end{array}$ \\
\hline $\begin{array}{l}\text { SSFP MR } \\
\text { imaging }\end{array}$ & $\begin{array}{c}\text { Myocardial viability and function, Ischemic and non ischemic } \\
\text { cardiomyopathy, congenital heart disease, coronary artery disease, } \\
\text { renal artery stenosis }\end{array}$ & $\begin{array}{c}\text { Requirement } \\
\text { of dedicated } \\
\text { personnel having } \\
\text { expertise in cardiac } \\
\text { imaging, post-pro- } \\
\text { cessing and inter- } \\
\text { pretation. }\end{array}$ & No exposure to ionizing radiation \\
\hline $\begin{array}{l}\text { Arterial spin } \\
\text { labeling with/ } \\
\text { without SSFP }\end{array}$ & $\begin{array}{l}\text { Cerebral, renal and cardiac perfusion, Cerebral blood flow, Renal } \\
\text { artery stenosis }\end{array}$ & $\begin{array}{l}\text { Poor temporal } \\
\text { resolution and } \\
\text { spatial coverage, } \\
\text { banding artifacts }\end{array}$ & $\begin{array}{l}\text { No contrast is required, When } \\
\text { combined with SSFP, it can be used as } \\
\text { an angiographic imaging }\end{array}$ \\
\hline
\end{tabular}

*FAST: Focused Assessment with Sonography for Trauma.

DVT: Deep Venous thrombosis.

TOF: Time of flight.

ICM: Intravascular contrast medium.

SSFP: Steady state Free Precision. 
Table 3: Preventive strategy to lower the risk of CIN as per EUR guideline 2011.

\begin{tabular}{|c|c|c|c|c|c|}
\hline \multirow{2}{*}{ Parameters } & \multicolumn{4}{|c|}{ Elective Procedure } & \multirow{2}{*}{ Emergency Procedure } \\
\hline & eGFR $>60 \mathrm{ml} / \mathrm{min}$ & eGFR $45-60 \mathrm{ml} / \mathrm{min}$ & eGFR $30-45 \mathrm{ml} / \mathrm{min}$ & eGFR $<30 \mathrm{ml} / \mathrm{min}$ & \\
\hline \multicolumn{6}{|c|}{ Metformin Use Per ESUR Guideline 2011} \\
\hline When to stop & Continue & $\begin{array}{l}\text { Intravenous contrast: } \\
\text { continue } \\
\text { Intraarterial contrast: stop } \\
\text { 48hrs prior to exposure }\end{array}$ & $\begin{array}{l}\text { Stop } 48 \mathrm{hrs} \text { prior to } \\
\text { exposure }\end{array}$ & $\begin{array}{l}\text { Metformin not } \\
\text { recommended }\end{array}$ & Stopped at time of exposure \\
\hline When to restart & Continue & $\begin{array}{l}\text { Intravenous contrast: } \\
\text { continue } \\
\text { Intraarterial contrast: } 48 \mathrm{hrs} \\
\text { after exposure }\end{array}$ & $\begin{array}{c}\text { After 48hrs restart, } \\
\text { if renal function at } \\
\text { baseline }\end{array}$ & & $\begin{array}{l}\text { After procedure, monitor } \\
\text { for sign of lactic acidosis. } \\
\text { Restart } 48 \mathrm{hrs} \text { after } \\
\text { exposure if renal function at } \\
\text { baseline }\end{array}$ \\
\hline \multicolumn{6}{|c|}{ Prophylactic Strategy Per EUR Guideline } \\
\hline $\begin{array}{l}\text { Intravenous (IV) } \\
\text { contrast }\end{array}$ & None & None & IV or oral hydration & IV hydration & \multirow{2}{*}{$\begin{array}{l}\text { If risk factors, } 300-500 \mathrm{ml} \mathrm{IV} \\
\text { hydration }\end{array}$} \\
\hline $\begin{array}{l}\text { Intra-arterial (IA) } \\
\text { contrast }\end{array}$ & None & Hydration & IV hydration & IV hydration & \\
\hline
\end{tabular}

a) Metformin Use: Metformin has not been recognized as independent risk factor for developing CIN, however serious complications like lactic acidosis can rarely develop in patients on metformin, if they subsequently develop AKI after contrast exposure. Whether it should be stopped in all patients anticipating contrast exposure or only in patients with underlying renal impairment and how earlier it should be stopped is still matter of controversy. The monogram for Glucophage (metformin) recommends that it should be discontinued at the time of or before the procedure in all patients, withheld for at least 48 hours subsequent to the procedure, and restarted only after confirmation of normal renal function [57]. The European Society of Urogenital Radiology (ESUR) (Table 3) and Canadian Association of Radiologist (CAR) consensus recommends holding metformin at the time contrast exposure in patient with normal renal function and 48 hours before in patients with preexisting chronic kidney disease $[48,58]$. However, ACR recommends withholding it for $48 \mathrm{hrs}$ before exposure only in patients with marked renal impairment (eGFR $\leq 30 \mathrm{~mL} / \mathrm{min} / 1.73 \mathrm{~m}^{2}$ ) or undergoing intra-arterial catheter studies and no need to discontinue or withhold if eGFR > 30 $\mathrm{mL} / \mathrm{min} 1.73 \mathrm{~m}^{2}$ ] [59].

b) End Stage Renal Disease (ESRD): Patient with ESRD on dialysis usually do not have functional kidneys and can receive intravascular contrast material without further risk of renal damage, however studies have speculated conversion of oliguric patient to anuria. Other consideration is risk of pulmonary edema and fluid overload after osmotic load, though it was reported in past when HOCMs were frequently used. However, whenever possible LOCM should be used as they are not protein bound and have low molecular weight and can be cleared by dialysis. Usually urgent dialysis is never indicated after CM in this population unless there is exposure to large volume of contrast and patient develops life threatening pulmonary edema or cardiac arrhythmia [60].

c) Screening baseline renal function: It is actually general practice to screen baseline renal function prior to contrast exposure; however it can lead to diagnosis or procedural delay, increase financial cost and patient discomfort. ACR recommends to screen renal function (e.g., serum creatinine, eGFR) prior to exposure to iodinated $\mathrm{CM}$ in only selected patients with high risk factors including age $>60$ year, patient with history of renal disease, renal cancer, renal surgery, patient on dialysis, patients with single kidney, hypertension on medical therapy and diabetes mellitus. Patient who do not have above-mentioned risk factors and require routine intravascular contrast do not require routine screening [61,62]. Choyle et al. [62] listed few risk factors (preexisting renal dysfunction, hypertension, gout, proteinuria and prior renal surgery) and found that if none of these factors are present $99 \%$ of patients had serum creatinine levels less than $1.7 \mathrm{mg} / \mathrm{dl}$ and $94 \%$ of patients had normal renal function [62]. However, ERBP guidelines recommend measuring baseline serum creatinine in all patients before an intervention and repeat levels 12 and 72 hours after contrast administration in high-risk patients [38]. The decision to repeat serum creatinine after procedure is a matter of debate. According to ESUR, renal function after contrast exposure should be assessed in 3 days, however some studies have documented that in certain patient populations particularly with diabetes mellitus and chronic kidney disease peak rise in 
creatinine levels is actually delayed, which demands prolonged renal function survey [58,63].

\section{Prevention of CIN}

There has been number of preventive measures to reduce incidence of CIN in high- risk population, however there is no clear consensus and current evidence remains inconclusive $[64,65]$. However, it has been agreed that identification of highrisk population is the foremost. Once this population is identified, best attempt should be done to minimize renal injury by stopping other nephrotoxic medications particularly NSAIDS, loop diuretics and Metformin at least 24-48hours prior to contrast exposure particularly if IA exposure is anticipated and in patients with baseline severe insufficiency $[47,57,58]$. Unfortunately, in emergent procedures it might not be possible to stop medications or delay the procedure, however when possible restarting the nephrotoxic medication should be delayed for at least 48 hours after or as deemed clinically appropriate (Figure 1).

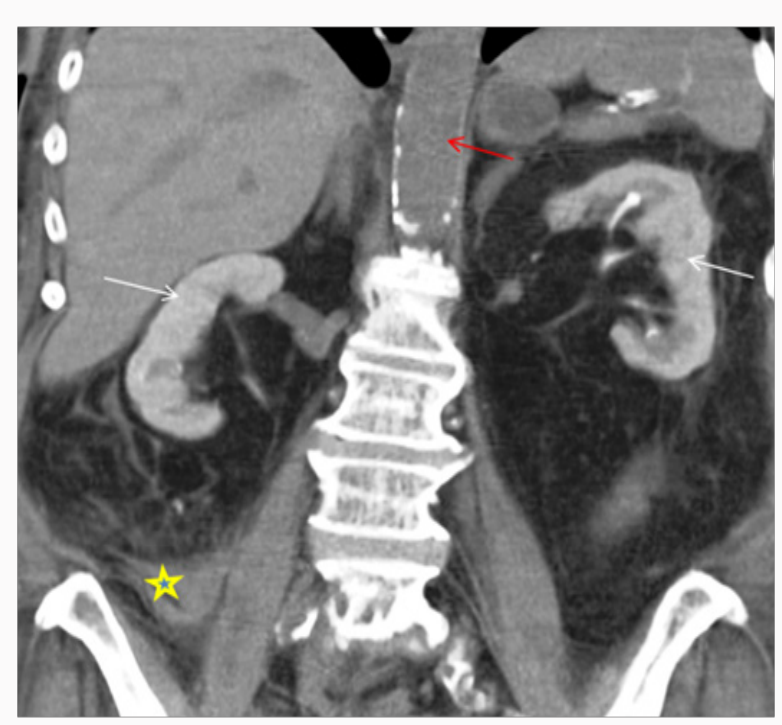

Figure 1: 68-year-old female with drop in hemoglobin status-post cardiac catheterization one day ago. Non-Contrast enhanced CT Abdomen demonstrating persistent nephrogram phase of enhancement from prior cardiac catheterization due to contrast induced nephropathy. Note hyperdense collection suggestive of an acute hematoma extending adjacent to RIGHT psoas muscle $\left(^{*}\right)$ lateral to the RIGHT psoas muscle continues with RIGHT iliac vessels, likely cause of drop in hemoglobin. Red arrow depicting no intra-vascular contrast media in the current study.

The cornerstone of practice to prevent CIN remains volume expansion. It is low-risk practice and carries few complications. Randomized trials have documented effectiveness of IV hydration with normal saline in the prevention of CIN. It should be given in all risk categories, particularly patients with an estimated GFR $<60 \mathrm{ml} / \mathrm{min} / 1.73 \mathrm{~m}^{2}$. It is postulated to promote diuresis, increase intravascular volume, induce vasodilation and suppress renin aldosterone axis. However, there is no fixed regimen and in general, starting it well before exposure and continuing even after procedure is the best practice. Oral volume expansion has shown some benefit, however evidence does not support it to be as effective as IV volume expansion. For isotonic saline administration, most studies suggest that $0.9 \%$ saline should be started at a rate of $1-1.5 \mathrm{~mL} / \mathrm{kg} / \mathrm{h}$ 3-12 $\mathrm{h}$ before and 6-12 $\mathrm{h}$ after contrast media exposure [66,67]. IV administration of sodium bicarbonate has also been studied for prevention of CIN; however recent data have shown conflicting and mixed results. The theoretical benefit of sodium bicarbonate is alkalization of tubular fluid and reduced production of free oxygen radicals, along with volume expansion. Most studies have suggested that it should be started at a rate of $3 \mathrm{~mL} / \mathrm{kg} / \mathrm{h} 1 \mathrm{~h}$ before and $1 \mathrm{~mL} /$ $\mathrm{kg} / \mathrm{h}$ for $6 \mathrm{~h}$ after contrast exposure. Though some studies have documented its beneficial effects, they have been critiqued for being single center, non-blinded and small studies $[67,68]$.

$\mathrm{N}$-acetylcysteine (NAC) also gained popularity for use to prevent CIN. It is believed to be direct free radicals scavenger, which improves blood flow through nitric oxide-mediated pathways. Its antioxidant and vasodilator actions are believed to protect against CIN. As compared to IV saline alone, low-dose NAC along with IV saline has shown significant decrease in CIN in patients receiving either IA or IV contrast. It is commonly employed agent in clinical setting in patients at high risk because of high tolerability, low cost, potential cardio protective properties, even in absence of clear scientific evidence. KDIGO 2012 guideline recommends using oral NAC with IV fluids in patients with high risk of CIN in setting of its low risk profile [38,69]. Algorithm showing preventive measures to be taken is shown in (Figure 2) Various other experimental pharmacologic agents have been studied for CIN prophylaxis including statin, ascorbic acid, tocopherol, dopamine, fenoldopam, theophylline, nebivolol, atrial natriuretic peptide and prostaglandin, however none of them have achieved clinical significant results [70]. Also, no beneficial effect of experimental procedures such as hemo filtration (HF) and prophylactic hemodialysis (HD) was 
found against CIN [71]. Moreover, prophylactic HD was found to be associated with increased CIN [71]. New investigational study 'Renal guard system' which is a fluid management device seems promising except for concern of electrolyte abnormalities and additional studies are needed before renal guard system can be implemented clinically [72,73].

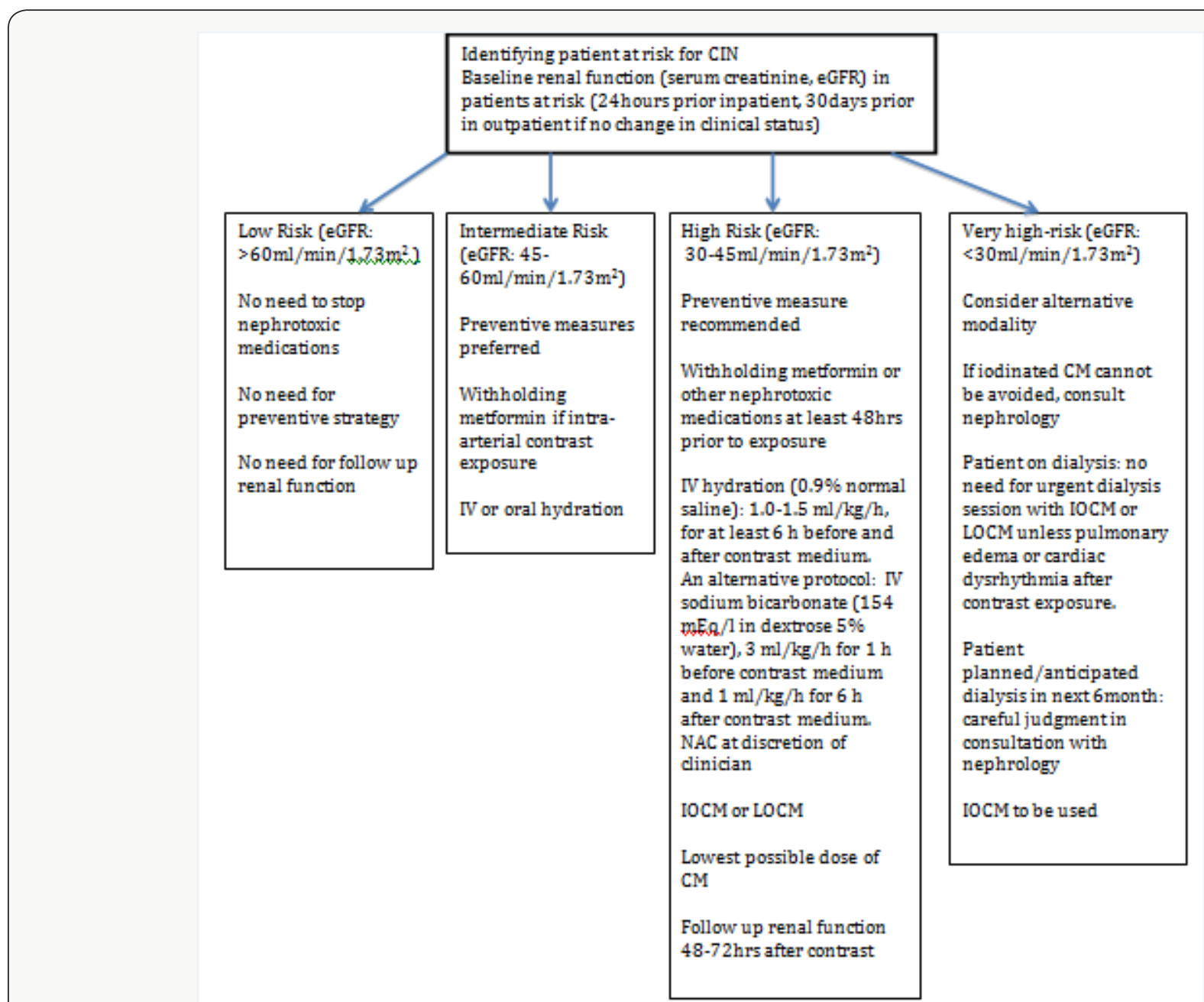

Figure 2: Flowchart for Risk stratification and preventive measures.

\section{Conclusion}

Clinicians should be well aware of CIN, which is potentially serious entity. Since there is no established treatment for CIN, every effort should be taken to prevent it from occurring by recognizing at risk population, weighing risk-benefit ratio in all patients, optimizing volume status prior to contrast exposure, avoiding simultaneous use of other nephrotoxic agents, using newer generation of $\mathrm{CM}$ and using lowest possible dose.

\section{References}

1. Mc Cullough PA, Wolyn R, Rocher LL, Levin RN, O Neill WW (1997) Acute renal failure after coronary intervention: incidence, risk factors, and relationship to mortality. Am J Med 103(5): 368-375.

2. Marenzi G, Lauri G, Assanelli E, Campodonico J, De Metrio M, et al. (2004) Contrast-induced nephropathy in patients undergoing primary angioplasty for acute myocardial infarction. J Am Coll Cardiol 44(9): 1780-1785.
3. Hinson JS, Ehmann MR, Fine DM, Fishman EK, Toerper MF, et al. (2017) Risk of acute kidney injury after intravenous contrast media administration. Ann Emerg Med 69(5): 577-586.

4. Karlsberg RP, Dohad SY, Sheng R (2010) Contrast-induced acute kidney injury (CI-AKI) following intra-arterial administration of iodinated contrast media. J Nephrol 23(6): 658-666.

5. Nyman U, Almén T, Jacobsson B, Aspelin P (2012) Are intravenous injections of contrast media really less nephrotoxic than intra-arterial injections? Eur Radiol 22(6): 1366-1371.

6. Nikolsky E, Mehran R, Turcot D, Aymong ED, Mintz GS, et al. (2004) Impact of chronic kidney disease on prognosis of patients with diabetes mellitus treated with percutaneous coronary intervention. Am J Cardiol 94(3): 300-305.

7. Parfrey PS, Griffiths SM, Barrett BJ, Paul MD, Genge M, et al. (1989) Contrast material-induced renal failure in patients with diabetes mellitus, renal insufficiency, or both. N Engl J Med 320(3): 143-149.

8. Polena S, Yang S, Alam R, Gricius J, Gupta JR, et al. (2005) Nephropathy in critically Ill patients without preexisting renal disease. Proc West Pharmacol Soc 48: 134-135. 
9. Mitchell AM, Jones AE, Tumlin JA, Kline JA (2010) Incidence of contrastinduced nephropathy after contrast-enhanced computed tomography in the outpatient setting. Clin J Am Soc Nephrol 5(1): 4-9.

10. Chuang F, Chen T, Wang I, Chuang C, Chang H, et al. (2009) Comparison of iodixanol and iohexol in patients undergoing intravenous pyelography: a prospective controlled study. Ren Fail 31(3): 181-188.

11. Rihal CS, Textor SC, Grill DE, Berger PB, Ting HH, et al. (2002) Incidence and prognostic importance of acute renal failure after percutaneous coronary intervention. Circulation 105(19): 2259-2264.

12. Chong E, Shen L, Poh K, Tan H (2012) Risk scoring system for prediction of contrast induced nephropathy in patients with pre-existing renal impairment undergoing percutaneous coronary intervention. Singapore Med J 53(3): 164-169.

13. Stacul F, van der Molen, Aart J, Reimer P, Webb JA, et al. (2011) Contrast induced nephropathy: updated ESUR contrast media safety committee guidelines. Eur Radiol 21(12): 2527-2541.

14. Thadhani R (1996) Acute renal failure. N Engl J Med 334(22): 14481460 .

15. Kellum JA, Levin N, Bouman C, Lameire N (2002) Developing a consensus classification system for acute renal failure. Curr Opin Crit Care 8(6): 509-514.

16. Mc Donald RJ, McDonald JS, Bida JP, Carter RE, Fleming CJ, et al. (2013) Intravenous contrast material-induced nephropathy: Causal or coincident phenomenon? Radiology 267(1): 106-118.

17. Barrett BJ, Parfrey PS (1994) Prevention of nephrotoxicity induced by radiocontrast agents. N Engl J Med 331(21): 1449-1450.

18. Mehta RL, Kellum JA, Shah SV, Molitoris BA, Ronco C, et al. (2007) Acute Kidney Injury Network: report of an initiative to improve outcomes in acute kidney injury. Crit care 11(2): R31.

19. Star RA (1998) Treatment of acute renal failure. Kidney Int 54(6): 1817 1831

20. Nelson A, Mackinnon B, Traynor J, Geddes C (2006) The relationship between serum creatinine and estimated glomerular filtration rate: implications for clinical practice. Scott Med J 51(4): 5-9.

21. Toprak O, Cirit M (2006) Risk factors for contrast-induced nephropathy. Kidney Blood Press Res 29(2): 84-93.

22. Tublin ME, Murphy ME, Tessler FN (1998) Current concepts in contrast media-induced nephropathy. AJR Am J Roentgenol 171(4): 933-939.

23. Love L, Johnson M, Bresler M, Nelson J, Olson M, et al. (1994) The persistent computed tomography nephrogram: its significance in the diagnosis of contrast-associated nephro toxicity. Br J Radiol 67(802): 951-957.

24. Ribichini F, Graziani M, Gambaro G, Pasoli P, Pighi M, et al. (2010) Early creatinine shifts predict contrast-induced nephropathy and persistent renal damage after angiography. Am J Med 123(8): 755-763.

25. Briguori C, Quintavalle C, Donnarumma E, Condorelli G (2014) Novel biomarkers for contrast-induced acute kidney injury. Biomed Res Int 568738.

26. Briguori C, Visconti G, Rivera NV, Focaccio A, Golia B, et al. (2010) Cystatin C and contrast-induced acute kidney injury. Circulation 121(19): 21172122.

27. Kronzon I, Saric M (2010) Cholesterol embolization syndrome. Circulation 122(6): 631-641.

28. Peer A, Averbukh Z, Berman S, Modai D, Averbukh M, Weissgarten J (2003) Contrast media augmented apoptosis of cultured renal mesangial, tubular, epithelial, endothelial, and hepatic cells. Invest Radiol 38(3): 177-182.
29. Bakris GL, Lass N, Gaber AO, Jones JD, Burnett JC (1990) Radiocontrast medium-induced declines in renal function: a role for oxygen free radicals. Am J Physiol 258: 115-120.

30. Zhang Y, Wang J, Yang X, Wang X, Zhang J, et al. (2012) The serial effect of iodinated contrast media on renal hemodynamics and oxygenation as evaluated by ASL and BOLD MRI. Contrast Media Mol Imaging 7(4): 418-425.

31. Senoo T, Motohiro M, Kamihata H, Yamamoto S, Isono T, et al. (2010) Contrast-induced nephropathy in patients undergoing emergency percutaneous coronary intervention for acute coronary syndrome. Am J Cardiol 105(5): 624-628.

32. Hardiek K, Katholi RE, Ramkumar V, Deitrick C (2001) Proximal tubule cell response to radiographic contrast media. Am J Physiol Renal Physiol 280(1): 61-70.

33. Schick CS, Haller C (1999) Comparative cytotoxicity of ionic and nonionic radiocontrast agents on MDCK cell monolayers in vitro. Nephrol Dial Transplant 14(2): 342-347.

34. Sabbahy ME, Vaidya VS(2011) Ischemic kidney injury and mechanisms of tissue repair. Wiley Interdiscip Rev Syst Biol Med 3(5): 606-618.

35. Manske CL, Sprafka JM, Strony JT, Wang Y (1990) Contrast nephropathy in azotemic diabetic patients undergoing coronary angiography. Am J Med 89(5): 615-620.

36. Davenport MS, Khalatbari S, Cohan RH, Ellis JH (2013) Contrast medium-induced nephrotoxicity risk assessment in adult inpatients: a comparison of serum creatinine level-and estimated glomerular filtration rate-based screening methods. Radiology 269(1): 92-100.

37. Lameire N, Adam A, Becker CR, Davidson C, Mc Cullough PA,et al. (2006) Baseline renal function screening. Am J Cardiol 98(6): 21-26.

38. Jörres A, John S, Lewington A, ter Wee PM, Vanholder R, et al. (2013) A European Renal Best Practice (ERBP) position statement on the Kidney Disease Improving Global Outcomes (KDIGO) clinical practice guidelines on acute kidney injury: part 2: renal replacement therapy. Nephrol Dial Transplant 28(12): 2940-2945.

39. Cigarroa RG, Lange RA, Williams RH, Hillis D (1989) Dosing of contrast material to prevent contrast nephropathy in patients with renal disease. Am J Med 86(6): 649-652.

40. Mehran R, Aymong ED, Nikolsky E, Lasic Z, Iakovou I, et al. (2004) A simple risk score for prediction of contrast-induced nephropathy after percutaneous coronary intervention: development and initial validation. J Am Coll Cardiol 44(7): 1393-1399.

41. Ranucci M, Castelvecchio S, Menicanti L, Frigiola A, Pelissero G (2009) Risk of assessing mortality risk in elective cardiac operations: age, creatinine, ejection fraction, and the law of parsimony. Circulation 119(24): 3053-3061.

42. Capodanno D, Ministeri M, Dipasqua F, Dalessandro V, Cumbo S, et al. (2016) Risk prediction of contrast-induced nephropathy by ACEF score in patients undergoing coronary catheterization. J Cardiovasc Med 17(7): 524-529.

43. Davidson C, Stacul F, Mc Cullough PA, Tumlin J, Adam A, et al. (2006) Contrast medium use. Am J Cardiol 98(6): 42-58.

44. Moore RD, Steinberg EP, Powe NR, Brinker JA, Fishman EK, et al. (1992) Nephrotoxicity of high-osmolality versus low-osmolality contrast media: randomized clinical trial. Radiology 182(3): 649-655.

45. Heinrich MC, Häberle L, Müller V, Bautz W, Uder M (2009) Nephrotoxicity of iso-osmolar iodixanol compared with nonionic low-osmolar contrast media: meta-analysis of randomized controlled trials. Radiology 250(1): 68-86.

46. Heemann U, Abramowicz D, Spasovski G, Vanholder R (2011) European Renal Best Practice (ERBP) Work Group on kidney transplantation. 
Endorsement of the Kidney Disease Improving Global Outcomes (KDIGO) guidelines on kidney transplantation: a European Renal Best Practice (ERBP) position statement. Nephrol Dial Transplant. 26(7) 2099-2106

47. Mc Cullough PA, Stacul F, Becker CR, Adam A, Lameire N, et al. (2006) Contrast-Induced Nephropathy (CIN) Consensus Working Panel: executive summary. Rev Cardiovasc Med Fall 7(4): 177-197.

48. Owen RJ, Hiremath S, Myers A, Fraser-Hill M, Barrett BJ (2014) Canadian Association of Radiologists consensus guidelines for the prevention of contrast-induced nephropathy: update 2012. Can Assoc Radiol J 65(2): 96-105.

49. Brown JR, Robb JF, Block CA, Schoolwerth AC, Kaplan AV,et al. (2010) Does safe dosing of iodinated contrast prevent contrast-induced acute kidney injury? Circ Cardiovasc Interv 3(4): 346-350.

50. Taliercio CP, Vlietstra RE, FiSHER LD, Burnett JC (1986) Risks for renal dysfunction with cardiac angiography. Ann Intern Med 4(4): 501-504.

51. Guitterez NV, Diaz A, Timmis GC, O Neill WW, Stevens MA, et al. (2002) Determinants of serum creatinine trajectory in acute contrast nephropathy. J Interv Cardiol 15(5): 349-354.

52. Rawson JV, Pelletier AL (2013) When to Order a Contrast-Enhanced CT. Am Fam Physician 88(5): 312-316.

53. Runge VM, Nitz WR, Trelles M (2013) Physics of Clinical MR Taught Through Images. Thieme.

54. Penfield JG, Reilly RF (2007) What nephrologists need to know about gadolinium. Nat Clin Pract Nephrol 3(12): 654-668.

55. Perazella MA (2009) Current status of gadolinium toxicity in patients with kidney disease. Clin J Am Soc Nephrol 4(2): 461-469.

56. Hawkins IF, Cho KJ, Caridi JG (2009) Carbon dioxide in angiography to reduce the risk of contrast-induced nephropathy. Radiol Clin North Am 47(5): 813-825.

57. (2016) US Food and Drug Administration. FDA Drug Safety Communication: FDA revises warnings regarding use of the diabetes medicine metformin in certain patients with reduced kidney function. US Department of Health and Human Services.

58. Stacul F, van der Molen AJ, Reimer P, Webb JA, Thomsen HS, et al. (2011) Contrast induced nephropathy: updated ESUR contrast media safety committee guidelines. Eur Radiol 21(12): 2527-2541.

59. (2017) American College of Radiology. ACR manual on contrast media. American College of Radiology; Version 10.3.

60. Younathan CM, Kaude JV, Cook MD, Shaw GS, Peterson JC (1994) Dialysis is not indicated immediately after administration of nonionic contrast agents in patients with end-stage renal disease treated by maintenance dialysis. AJR Am J Roentgenol 163(4): 969-971.
61. Tippins RB, Torres WE, Baumgartner BR, Baumgarten DA (2000) Are screening serum creatinine levels necessary prior to outpatient CT examinations? Radiology 216(2): 481-484.

62. Choyke PL, Cady J, DePollar SL, Austin H (1998) Determination of serum creatinine prior to iodinated contrast media: is it necessary in all patients? Tech Urol 4(2): 65-69.

63. Reddan D, Laville M, Garovic VD (2009) Contrast-induced nephropathy and its prevention: what do we really know from evidence-based findings? J Nephrol 22(3): 333-351.

64. Kelly AM, Dwamena B, Cronin P, Bernstein SJ, Carlos RC (2008) Metaanalysis: Effectiveness of Drugs for Preventing Contrast-Induced Nephropathy. Ann Intern Med 148(4): 284-294.

65. Subramaniam RM, Suarez-Cuervo C, Wilson RF, Turban S, Zhang A, et al. (2016) Effectiveness of Prevention Strategies for Contrast-Induced NephropathyA Systematic Review and Meta-analysis Effectiveness of Prevention Strategies for CIN. Ann Intern Med 164(6): 406-416.

66. Mueller C, Buerkle G, Buettner HJ, Petersen J, Perruchoud AP, et al. (2002) Prevention of contrast media-associated nephropathy: randomized comparison of 2 hydration regimens in 1620 patients undergoing coronary angioplasty. Arch Intern Med 162(3): 329-36.

67. Ozcan EE, Guneri S, Akdeniz B, Akyıldız IZ, Senaslan O, et al. (2007) Sodium bicarbonate, $\mathrm{N}$-acetylcysteine, and saline for prevention of radiocontrast-induced nephropathy. A comparison of 3 regimens for protecting contrast-induced nephropathy in patients undergoing coronary procedures. A single-center prospective controlled trial. Am Heart J 154(3): 539-544.

68. Brar SS, Hiremath S, Dangas G, Mehran R, Brar SK, et al. (2009) Sodium bicarbonate for the prevention of contrast induced-acute kidney injury: a systematic review and meta-analysis. Clin J Am Soc Nephrol 4(10): 1584-1592.

69. Heguilén RM, Liste AA, Payaslian M, Ortemberg MG, Albarracín LM,et al (2013) $\mathrm{N}$-acethyl-cysteine reduces the occurrence of contrast-induced acute kidney injury in patients with renal dysfunction: a single-center randomized controlled trial. Clin Exp Nephrol 17(3): 396-404.

70. Pattharanitima P, Tasanarong A (2014) Pharmacological Strategies to Prevent Contrast-Induced Acute Kidney Injury. Biomed Res Int

71. Cruz DN, Goh CY, Marenzi G, Corradi V, Ronco C, et al. (2012) Renal replacement therapies for prevention of radiocontrast-induced nephropathy: a systematic review. The American journal of medicine 125(1): 66-78.

72. Marenzi G (2009) Prevention of contrast-induced nephropathy and management of high-risk patients. Giornale italiano di cardiologia (2006) 10(2): 88-96.

73. Rumack CM, Wilson SR, Charboneau JW, Levine D (2014) Diagnostic ultrasound fourth edition.
This work is licensed under Creative Commons Attribution 4.0 License

To Submit Your Article Click Here:

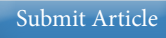

DOI: $10.32474 / J U N S .2018 .01 .000103$

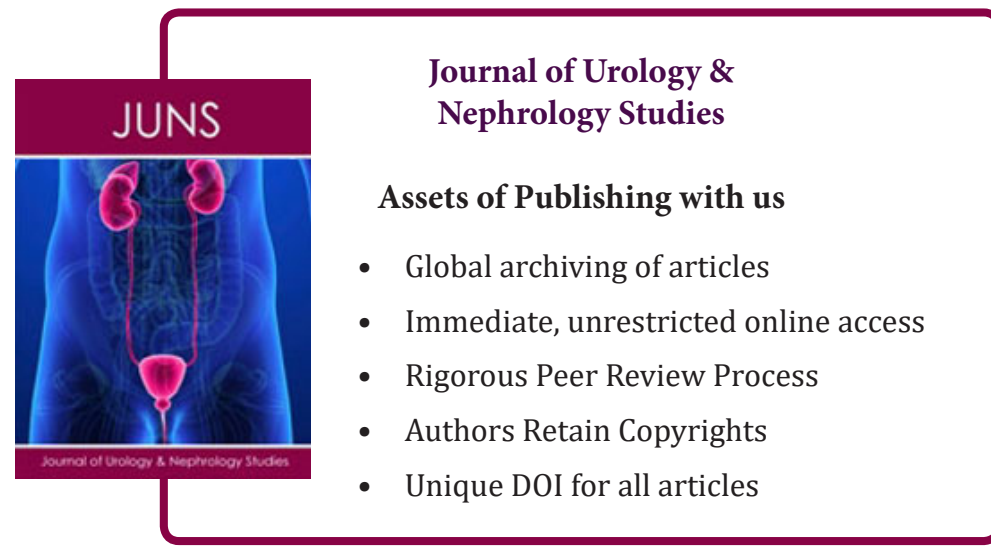

Citation: Sonali G, Pradeep G, Nishant G, Harpreet S, Vivek K. Contrast-Induced Nephropathy: Current practice. J Urol Neph St 1(1)- 2018. JUNS. 